\title{
Connect, Motivate, Communicate: A Foundation for Gamification in Planning Communication
}

\section{SIGRADI2018 TECHNOPOLITICAS \\ xxii congresso da sociedade iberoamericana de gráfica digital 22th conference of the iberoamerican society of digital graphics 07|08|09|novembro|2018 iau usp | são carlos | sp br}

\author{
Sarah Louise Jenney \\ Technical University of Munich | Germany | s.jenney@tum.de \\ Michael Mühlhaus \\ Technical University of Munich | Germany | Michael.muehlhaus@tum.de \\ Frank Petzold \\ Technical University of Munich | Germany | petzold@tum.de
}

\begin{abstract}
Planning in the urban context is always a complex task in which the diverse interests of different stakeholders have to be weighed up against each other. For this to happen, communication is the key leading to successful and sustainable solutions. Often objective factors like the number and diversity of participating stakeholders is the benchmark for successful planning processes. We examine the motivational factors of the different main stakeholder groups and give an insight in the complex system of motivational and hindering factors that need to be considered when designing engaging sensible and sustainable exchange of knowledge and interests.
\end{abstract}

Keywords: Motivation; Gamification; Communication; Participation; Collaboration.

\section{INTRODUCTION}

Within the realm of urban planning, many different stakeholders with varying backgrounds, knowledge-levels, and interests, as well as personal and institutional cultures are brought together, to build and rebuild more than just urban spaces. One of the most fundamental challenges is the complexity of the relationships between these different groups. As no single stakeholder possesses all forms of knowledge on the different aspects of planning, communication becomes essential, "it has become clear that communication is not a quality in planning, but a necessary medium for the success and sustainability of planning solutions; 'communication is not everything, but planning without communication is nothing' (Quote translated by Authors; Selle 2005)" (Muehlhaus et al., 2018).

Current research projects at the Technical University of Munich include USP (Urban Strategy Playground), which develops new tools supporting decision-making in early strategic design phases, and Game.UP, which researches potentials of gamification in communication processes in planning between different stakeholders. Gamification is the use of game thinking to "engage users and solve problems" (Zichermann \& Cunningham, 2011) and it can help bridge the communication gap between different groups when used as a tool or interface. Game-full environments "can lead to a broader consensus in problem-solving contexts as it enables us to view a problem from different angles, supporting objective reasoning and fostering motivation. This improves understanding and ones' willingness to compromise and is therefore well suited in mediation situations such as planning" (Jenney \& Petzold, 2017), and it can balance the asymmetrical levels of power in planning decisionmaking.

Gamification can be implemented to improve interaction possibilities in the sharing of information; to motivate the public to participate in planning processes by addressing critical aspects of intrinsic motivation; provide feedback mechanisms; and benefit collaboration not only between the public and planning authorities (Jenney \& Petzold, 2017). However, before such game-full, engaging environments can be integrated in planning communication in a sensible and sustainable way, the question that needs to be addressed is how different stakeholders can be reached, what requirements they have and what motivates them to communicate with each other. This paper builds on theories found in the related literature to form a foundation for the development of tools to improve planning communication for evaluation and verification purposes. An intensive literature review was conducted on communication mechanisms, intercultural communication, human perception, motivation, and learning; coupled with previous research into participation, gamification, and information visualisation. We aim to identify motivational factors and map these to the different stakeholders in planning (the public, planners and city planning authorities) to enable a more targeted development of solutions to communication challenges.

\section{STAKEHOLDERS}

The three main groups identified, shape building development and space in early planning phases within the context of urban planning in Germany. Public and 
private building initiators are not considered a separate group in this context because they can be associated with one or more of the other three groups.

\section{PUBLIC}

When we talk of the public, we do not focus on the inhabitants, nor the direct neighbours of a building to be planned because these people must be informed, by law, of any developments. We are also not talking about activists, who have strong interests in specific subjects and are highly aware of the issues which interest them. We are talking about individuals and family units who are affected by an urban development intervention and driven by individualistic more immediate motivators.

\section{PLANNERS}

In Europe, the landscape of planning offices is highly fragmented with a large percentage of small and mediumsized companies. As planners of the built environment, they are able to shape rural and to a greater degree urban landscapes and the way in which people interact within that space, collectively enhancing these environments. However, as companies, planners need to generate revenue like any other organisation and are often driven by more individualistic motivators.

\section{POLITICS}

The city plans on multiple scales from regional planning to building on specific sites. In this context, we are looking at the city from the latter scale, but as an active producer of space, through for example regulation, legislation, planning application determination, and planning initiator. It acts collectively as a representative of the public to achieve planning goals, ensure and enforce safety measures, support the social environment, and protect the natural one. Politics can also refer to collective groups of the public promoting a distinct cause.

\section{INFLUENCING FACTORS}

Motivation theory distinguishes between three factors of motivation: personal factors, situational factors, and the interaction between the two. Personal factors include "universal behavioral tendencies and needs, motive dispositions (implicit motives) that distinguish between individuals, and the goals (explicit motives) that individuals adopt and pursue" (Heckhausen \& Heckhausen, 2008, p3). Motivations of an individual can change as they develop over time. Situational factors, in contrast, account for the opportunities and constraints of a situation. "Every positive or negative outcome that a situation can promise or signal to an individual is called an 'incentive' and has 'demand characteristics' for an appropriate action. Incentives may be associated with the action itself, its outcome, or various consequences of an action outcome" (Heckhausen \& Heckhausen, 2008, p. 4). It is impossible to separate these two factors from each other, because it is impossible to define comparable units for each domain and any units defined will favour the importance of the factor they suit more, the "situation" is not objective but rather subjective, and the observer will observe and interpret behaviour subjectively too. The expectancy-value theory can account for an interaction of both personal and situational factors in models predicting behaviour. Although expectancy is subjective, "the individual aspires to the goal with the highest possible incentive value, considering the probability of its attainment. Whether or not a situation acts as an incentive for a specific individual depends on whether or not it corresponds with that person's implicit and explicit motives" (Heckhausen \& Heckhausen, 2008, p6). However, a motivational tendency alone compels no action. While motivation can be considered as the "setting and selection of goals" (Heckhausen \& Heckhausen, 2008, p6), volition describes goal implementation. The action-phase model describes the transition from intention formation or deliberation, to the initiation of action, to the reflection of its success or failure (Heckhausen \& Heckhausen, 2008). The following section looks at various personal and situational factors which play a role in motivation and participation in architectural communication.

\section{NEEDS AND DRIVES}

Collabouration, communication, and participation will always require extra effort and compromise or trade-offs (Knieling et al., 2003), making it essential to address motivational issues within this context. Maslow's hierarchy of needs (Maslow, 1943) ranks human needs from physiological, safety, love/ belonging, esteem, to selfactualisation. He argues that each step must be satisfied before the next step can be reached, so basic physical needs must be fulfilled before planning stakeholders can interact with planning as a subject. Deci \& Ryan's (2010) model of motivation takes it one step further and expresses a basic need to achieve self-determination. Intrinsic motivation is governed by internal forces, is natural, and a drive towards this. To experience intrinsic motivation experiencing one's own competence, relatedness to others, and autonomy are essential. DeCaro \& Stokes (2013) link intrinsic motivation to improved performance in environmental responsibility and policy compliance. They suggest in their paper on public participation and institutional fit that "individuals are more likely to internalize norms and institutions in social contexts that satisfy their needs" (p. 3), therefore satisfying intrinsic motivation by aligning personal and institutional goals to increase willingness to pool information, attendance/ participation and cooperative behaviour (DeCaro \& Stokes, 2013).

People are internally motivated by different things. Borrowed from social psychology Schell (2008) describes the interpersonal circumplex, which is a model designed to identify, organise and analyse interpersonal traits, motivators, and behaviour. Many means of measurement have been developed to map people's behaviour on this model, with two main axes dominant/ submissive and friendly or warm/ hostile (Leary, 1957). There are eight personality traits in this model: leading, nurturant, cooperative, docile, self-effacing, distrustful, critical, and self-enhancing. Bartle (1996) in his research of interaction in games, developed four personality traits along the axes acting/ interacting and world/ player: achiever, explorer, socialiser, and killer. Both these models display competitive traits, e.g. leading, self-enhancing, and achiever; cooperative traits, e.g. nurturant, cooperative, socialiser; and hostile traits, e.g. distrustful, critical, killer. Where the models differ is in their fourth category. In the interpersonal circumplex, the traits docile and self-effacing are introverted. Bartle, by contrast, describes his fourth category as "explorer," although it can be argued, that 

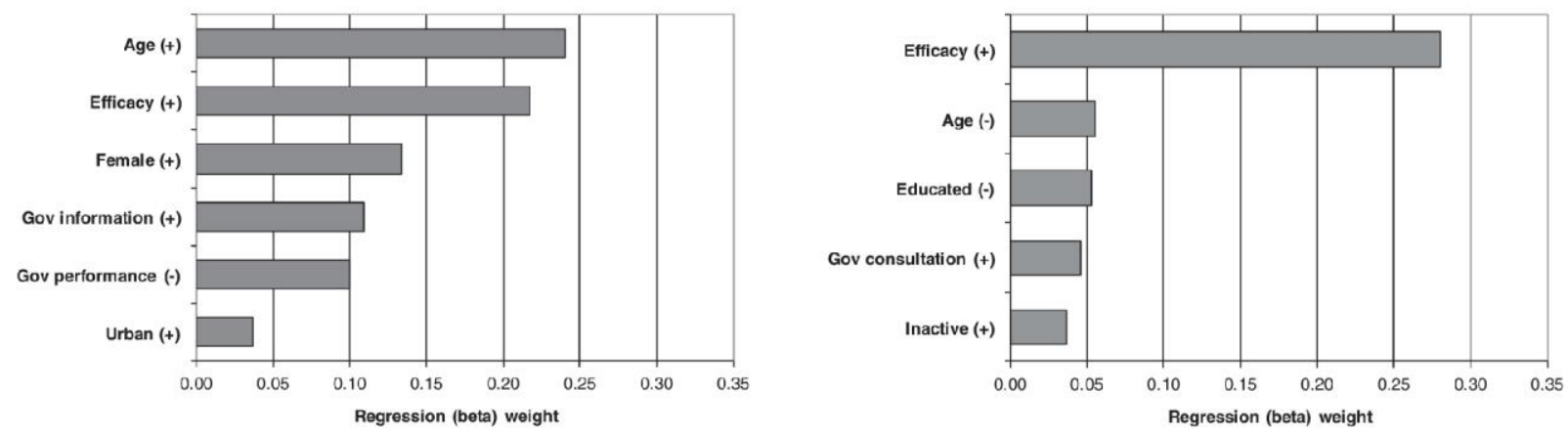

Figure 1: left: Key drivers (beta weights) of individual co-production (Bovaird et al., 2014, p. 12); right: Key drivers (beta weights) of collective co-production (Bovaird et al., 2014, p. 13).

exploration is a more introverted form of interaction with the world as it is possible to explore together but also alone. This theory is supported by Morschheuser (2017), who states that "individuals' behaviors can be cooperative [...], competitive [...], or individualistic" (p. 14).

\section{DECISION MAKING}

Decision-making is irrational and governed by multiple factors. Decision-making is often based on the biases of our intuition and experience, meaning we assume certain things without thinking about them (Kahneman, 2011). This is due to the automatic or survival part of our brain. The other part of our brain is rational and logical. But thinking logically or "slow" (Kahneman, 2011) takes effort, affecting the body, attention, and energy. Many fields including cognitive science, behavioural economics, perception, and psychology study how we take "fast" (Kahneman, 2011) decisions and a number of behavioural laws have been identified.

- Loss aversion describes the effect that we interpret loss greater than gain, meaning we are more likely to see what we might lose than what we could gain from a changing situation.

- Anchoring is the effect that initially presented data will bias the data following it.

- The science of availability is that if one hears about something often, it is perceived to be important and probable.

- $\quad$ Framing describes the concept that the same facts presented in different contexts will be interpreted differently.

- $\quad$ Finally, sunk cost describes the effect that if one has invested in something, be it through time or money, one is more likely to keep it/ keep at it, because of the cost and therefore the value it represents to that person.

These psychological factors attribute to "rational ignorance" (Downs, 1957), which describes a rational choice not to participate or collabourate as the effort and cost involved in accessing, understanding and logically reevaluating "fast" conclusions, greatly outweighs the perceived benefits of these actions. As a consequence, it can be hard to find a representative number of participants in planning processes, especially from the public group (Deutscher Städtetag, 2013). Cultural norms of decision making also play a major role in decisionmaking processes, where individualistic societies will respond very differently to collective societies when collabourating (Bannys, 2012). It is therefore clear that for collabouration to occur all participants must see a benefit in cooperation, but also that all have to actively participate (Bischoff et al., 1996).

\section{CO-PRODUCTION}

Co-production is defined in the context of public services by Bovaird et al. (2014), quoting Governance International (www.govint.org), as "professionals and citizens making better use of each other's assets, resources and contributions to achieve better outcomes or improved efficiency" (Bovaird et al., 2014, p. 5). In relation to urban planning we interpret co-production as collabouration, based on van Gassel et al.'s (2014) definition, "a creative process undertaken by two or more individuals, sharing their collective skills, expertise, understanding and knowledge (information) in an atmosphere of openness, honesty, trust, and mutual respect, to jointly deliver the best solution that meets their common goal" (p. 85). Bovaird et al. (2014) identified "a major gulf between current levels of individual and collective co-production" (p. 19), which are driven by different motivators. They "define collective co-production as the joint action of citizens to support services and achieve outcomes, while individual co-production covers those actions not jointly undertaken" (Bovaird et al., 2014, p. 5). In a quantitative study, focussing on the areas of health, community safety, and care of the local environment, based on five European countries including the United Kingdom, Germany, France, the Czech Republic, and Denmark, they identified the following influencing factors, offer possible reasons for the results, and compare their findings to others documented in literature.
3 
Key drivers for individual co-production (see Figure 1) in order of importance: age + , efficacy + , female + , government information +, government performance -, and urban + (Bovaird et al., 2014, p. 12). Older people are more likely to participate in individual co-production than younger people. If people believe they can make a difference, it increases their likelihood of participating in individual co-production. Women are more likely to participate, as are people who are satisfied with government information and those living in urban areas. Satisfaction with government performance has a negative effect, meaning people who are satisfied with their situation will be less likely to participate in individual coproduction.

Key drivers for collective co-production (see Figure 1) in order of importance: efficacy + as the most important by far, age -, education -, government consultation + , inactive + (Bovaird et al., 2014, p. 13). The belief that people can make a difference is the most important factor in collective co-production. Younger people are more likely to participate than older people in collective co-production, as are less educated people. Satisfaction with government consultation and inactivity in the workforce are positive drivers of participation. There are slight cultural differences in the data. For example, when looking at Germany, the relationship between government performance and individual co-production is slightly less negative, the relationship between government information and individual co-production is not significant, and the relationship between age and collective coproduction is almost neutral.

These different motivators suggest that different participation approaches are required to reach different stakeholder. DeCaro \& Stokes (2013) support this theory when they explain that "social-economic systems are immensely complex and dynamic, leading to variation in stakeholder beliefs, preferences, and goals that may influence subjective definitions of participation. Therefore, the best approach may be one that employs multiple modes of citizen engagement, phases of evaluation, and adaptive tailoring as the process unfolds (cf. Walkerden 2005, Stringer et al. 2006)" (p. 14).

\section{EXPERT VS. LAYMAN}

Common behaviour for those who have knowledge, is to not only assume others have that knowledge, but overestimate how widely it is spread, and the depth others have in the area (Rambow 2000). Knowledge can take different forms, such as knowledge on goals and values, knowledge on content and facts, clarifying knowledge which expresses the connections between different knowledge, and instrumental knowledge which describes the methods in which knowledge can be implemented (Bischoff et al., 1996). Communication in planning is highly specialised and mostly visual, taking the form of plans, sections, and elevations for example but only display specific forms of knowledge. To avoid misunderstanding and transfer knowledge these visualisations are full of code and convention; arbitrary signs which must be learned (Ware 2013) and act as a form of redundancy. This is the semantic part of what is known as the visual-semantic communication gap (Rambow 2000). Laymen have by definition not learned the codes and conventions of the planning culture, making it difficult for them to understand planning information and visualisation. In addition to this, planners use twodimensional plans to communicate three-dimensional spaces. This is changing with BIM (Building Information Modelling) regulation but remains an issue in everyday practice. Planners, like any other professionals, use technical terms in the communication of their projects. Where they differ from others is in their strong use of metaphors to describe abstract spaces, verbally visualising them (Rambow 2000). A further distinction between experts and laymen in planning is their perception of the built environment. Laymen refer to iconic buildings as architecture, not their everyday environments. They refer to buildings descriptively. Experts in contrast link architecture to their every-day surroundings. They are able to "read" buildings and organise and refer to them domain specifically (Rambow 2000).

These are all arbitrary factors, as defined by Ware (2013), and relate to learning and culture. Sensory factors are the opposite and are universally understood (Ware 2013). Both of these factors play a significant role in understanding and the transition from layman to expert.

\section{IMPLICATIONS}

\section{PUBLIC}

Members of the public, according to the study conducted by Bovaird et al. (2014), are more likely to be involved in individual co-production than collective co-production. When considering collective co-production within a planning context, it can be argued, however, that if members of the public are acting in organisations of a collective co-production nature, such as activist groups, they transition to the group of politics. Bovaird et al. (2014) suggest, according to Needham \& Carr (2009) and Fox et al. (2013), that "to encourage collective co-production in public services would appear to suggest customised services to fit the circumstances of individual service users and then help for them to visualise and rehearse what it would be like to work more closely with others" ( $p$. 20) and that, according Staples et al. (1999), "those who already have a high sense of self-efficacy may be particularly effective as mentors" (p. 20). The public relationship and perception towards both planners and politics appears to be the same, based on this research.

Loss aversion on the side of the public is a strong inhibitor in planning. It is clear that often planning decisions are not communicated in a way that the public can see or value the change and don't address the public fear of loss satisfactorily. The public is susceptible in particular to aspects such as anchoring and the science of availability, and experience difficulties with interpreting planning terminology, code, and convention all of which contribute to the effect of rational ignorance. Framing information holds a potential which is currently not utilised by the public, due to factors such as loss aversion, understanding, and convention. This factor, however, holds potential, as it enables planners and politics to address the actual issues.

\section{PLANNERS}

Planners work more collectively in co-production. In planning, face-to-face discussion is a vital part of the 


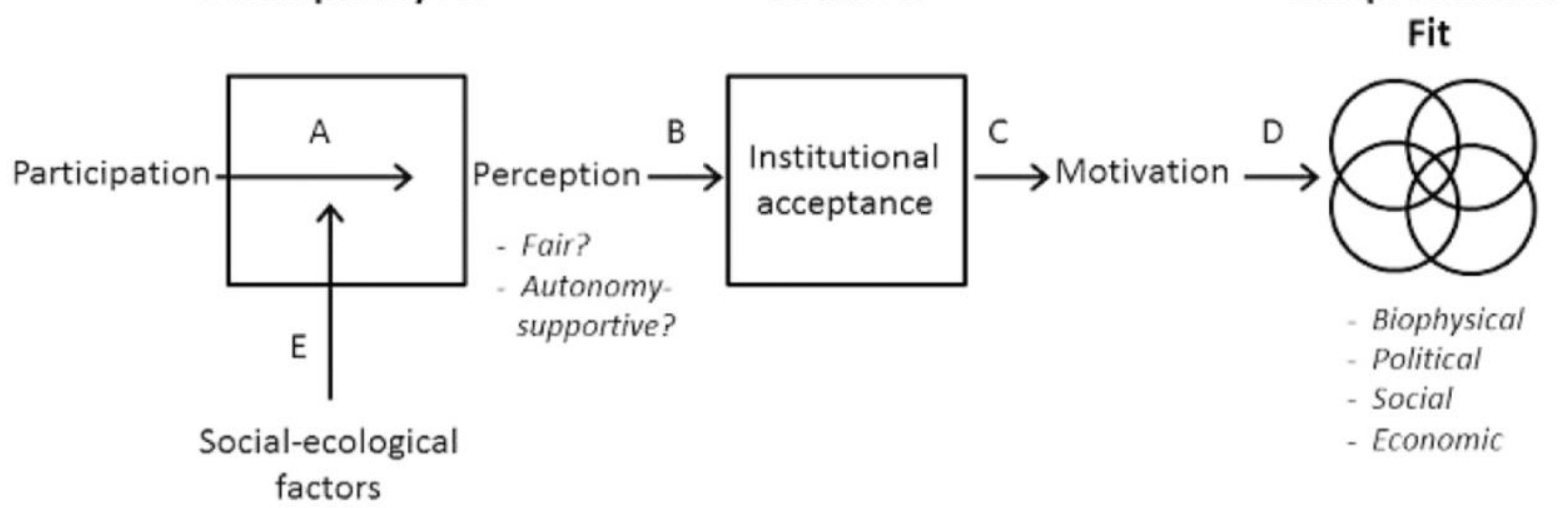

Figure 2: Behavioral process model linking participatory fit, social fit, and comprehensive fit (DeCaro \& Stokes, 2013, p. 2).

process to discuss next steps and challenges that may have arisen. However, individual co-production is also very common for example in the sequential project development processes between architect and engineer. The publics' relationship to planners/ politics is defined on the planner/ politics side. Planners sometimes co-produce with the public collectively in information, mediation and participation events, but like with the collective coproduction directed and offered by politics, a substantial problem with these processes is that the public don't parttake (Förster 2014).

Other factors that play into this is the loss aversion factor which planners have towards the public. The public as laymen to planning often want things which "ruin" planners' concepts or are not possible due to other factors. But the potential gain is high when considering that the public is expert on local challenges and needs. Planners can also experience loss aversion from a legislative and regulatory perspective in their relationship with politics. Within the professional environment aspects such as anchoring, the science of availability and technical terminology, code, and convention play little role, but they can lead to miscommunications with the public. Framing information, factors of sunk cost, and competition are more important within this group than it is for the public.

\section{POLITICS}

It is in the interest of politics to work in and offer collectivecoproduction opportunities, especially within their relationship with the public. "Identifying policies and initiatives which reinforce self-efficacy is therefore potentially attractive. There is already a long literature on this approach in the field of behaviour change" and "the positive effects on individual and collective co-production of government information and consultation give encouraging weight to initiatives seeking to engage citizens positively in civic affairs" (Bovaird et al. 2014, p. 20). Co-production between politics and planners is less common, but where it occurs, it occurs in both forms on a professional basis.

There are active movements within politics to strengthen co-production between themselves and the public. To promote and motivate towards individual and collective co-production should be considered. To achieve an even distribution of public representatives, different strategies need to be implemented to target specific groups (see the chapter on co-production). The public has valuable local knowledge on the challenges of the spaces they inhabit, and similarly, planners have valuable knowledge on the building process. Here a stronger collabouration between politics and planners could be promoted and developed too. Politics as a professional environment acts similar to planners when considering factors of anchoring, framing, and convention. The sunk cost factor, however, is of greater significance.

\section{DISCUSSION}

In urban planning we have different stakeholders with different needs and interests and therefore, different motivations, coming together to create space. This paper set out to identify the motivations and needs of the three main stakeholder groups; the public, planners, and city planning authorities or politics. Public stakeholders are individually and personally motivated, to enforce actions supporting self-interest (Bischoff et al., 1996). Where this is not possible due to conflicts of interest, procedural justice must be attained to achieve acceptance and trust in institutional decision-making (DeCaro \& Stokes, 2013). Whilst there is a culture of respecting social interests within the planning community, planners are predominantly motivated by economic factors. They are motivated to participate in actions which promote efficiency, especially by reducing effort associated with the revision of plans and designs (Bischoff et al., 1996). Planning authorities or politics, see cooperative planning as a "constitutional element of an active representative democracy and a substantial premise for sustainable and integrative city development" (Quote translated by authors, Deutscher Städtetag, 2013). Politics is motivated to create transparent planning processes which generate acceptance for development proposals and utilise local knowledge (VDI 2017). There has been a shift in recent years in planning processes to initiate communication among the different stakeholders in earlier planning phases. There are many reasons for this, for example, a higher degree of influence for the participants connected 
with lower cost for idea adaptation than in later planning phases.

Public participation is often associated with objective factors such as the number and diversity of stakeholders and is linked to degrees of participation such as Arnstein's (1996) ladder of participation (DeCaro \& Stokes, 2013). Following this line of reasoning, it is logical to assume that higher degrees of participation, which are associated with higher decision power, leads to more successful participation. This would mean that participation processes which offer high degrees of power would be more successful. DeCare \& Stokes (2013) demonstrate that this is not always the case and suggest, the reason for this is that it ignores motivational factors. In their framework (see Figure 2), they argue that when people's inherent psychological needs for procedural justice and self-determination are met, people perceive an institution as fair and autonomy-supportive (link A of Figure 2), which in turn promotes institutional acceptance (link B of Figure 2). This motivates people to participate more fully in institutional participation processes (links C and D of Figure 2).

However, DeCare \& Stokes (2013) also state, that "what citizens find acceptable will not always be best for the environment" (p. 14). The aim of participation must be to incorporate multiple perspectives on a topic (DeCaro and Stokes, 2013; Bischoff et al., 1996). This is not only true for the planner or political relationship with the public, but also between the professional institutions. Studies in the field of urban and architectural planning indicate that in both professional meetings (van Gassel et al., 2014) and public participation processes (Bischoff et al., 1996) factors such as having a defined goal, who is present, how the meeting is held or controlled, outcome requirements and what tools and methods are implemented have a great effect on the success of these procedures. "Cultural norms of decision-making control; class and gender; nature and salience of the [environmental] problem; political upheaval and natural disaster, and many other factors may all influence people's subjective definitions of 'participation'" (DeCaro \& Stokes, 2013, p. 13-14). The motivations of different stakeholders form a complex system which needs to be taken into consideration when creating collabourative and participatory processes within planning. One method is the integration of motivational factors within the design of the tools and processes used for collabouration and participation. In this way, participation is defined and framed by these factors. This paper builds on theories found in planning and related literature. Current research projects such as Game.UP and Urban Strategy Playground at the Technical University of Munich are developing such tools for evaluation and verification purposes.

\section{REFERENCES}

Arnstein, S. (1969). A Ladder Of Citizen Participation. Journal of the American Planning Association, 53, 216-224

Bannys, F. (2012). Interkulturelles Management. Konzepte und Werkzeuge für die Praxis. 1. Auflage. Weinheim, Germany: WILEY-VCH Verlag GmbH \& Co. KGaA.

Bartle, R. (1996). Hearts, clubs, diamonds, spades: Players who suit MUDs. Journal of MUD research.
Bischoff, A., Selle, K., \& Sinning, H. (1996). Informieren, Beteiligen, Kooperieren. Kommunikation in Planungsprozessen.

Bovaird, T., Van Ryzin, G., Loeffler, E., \& Parrado, S. (2015). Activating Citizens to Participate in Collective Co-Production of Public Services. Journal of Social Policy, 44(1), 1-23.

DeCaro, D., Stokes, M. (2013). Public Participation and Institutional Fit. A Social - Psychological Perspective. In E\&S 18 (4). DOI: 10.5751/ES-05837-180440.

Deci, E. \& Ryan, R. (2010). Self-Determination. In The Corsini Encyclopedia of Psychology (eds I. B. Weiner and W. E. Craighead). doi:10.1002/9780470479216.corpsy0834.

Deutscher Städtetag (2013). Beteiligungskultur in der integrierten Stadtentwicklung. Retrieved on 24th December 2017 from http://www.staedtetag.de/imperia/md/content/dst/veroeffentlic hungen/mat/mat_beteiligungskultur_2013_web.pdf

Downs, A. (1957). An Economic Theory of Political Action in a Democracy. Journal of Political Economy, 65(2), 135-150.

Förster, A. (2014). Planungsprozesse wirkungsvoller gestalten. Wirkungen, Bausteine und Stellgrößen kommunikativer planerischer Methoden. Dissertation. Technische Universität München, München. Lehrstuhl für Raumentwicklung.

Heckhausen, J., Heckhausen, H. (2008). Motivation and Action, 2nd ed. Cambridge, University Press, Cambridge.

Jenney, S.L., Petzold, F. (2017). Question of Perspective: Information Visualisation in Games and its Possible Application in Planning Communication. CAADFu- tures 2017, Istanbul, pp. 66-83.

Kahneman, D. (2011). Thinking, fast and slow. Farrar, Straus and Giroux, New York.

Knieling, J., Fürst, D., Danielzyk, R. (2003). Kooperative Handlungsformen in der Regionalplanung. Zur Praxis der Regionalplanung in Deutschland. Dortmunder Vertrieb für Bau- und Planungsliteratur (Regio spezial).

Lawson, B. (2003). The language of space. Repr. Oxford. Architectural Press.

Leary, T. (1957). Interpersonal diagnosis of personality; a functional theory and methodology for personality evaluation. Oxford, England: Ronald Press.

Maslow, A. (1943). A theory of human motivation. Psychological Review, 50(4), 370-396.

Morschheuser, B. (2017). The Gamification of Crowdsourcing Systems. Empirical Investigations and Design. Karlsruher Institut für Technologie (KIT).

Mühlhaus, M., Jenney, S.L. and Petzold, F. (2018). Take a Look through my Eyes: An Augmented Reality Planning Communication System. Proceedings of CAADRIA 2018, Peking, pp. 379-388.

Rambow, R. (2000). Experten-Laien-Kommunikation in der Architektur. Waxmann, Münster.

Schell, J. (2010). The Art of Game Design: A book of lenses. Elsevier Inc., Amsterdam.

Selle, K. (2005). Planen, Steuern, Entwickeln. Über den Beitrag öffentlicher Akteure zur Entwicklung von Stadt und Land. Dortmunder Vertrieb für Bau- und Planungsliteratur, Dortmund.

Tufte, E.R. (2005). Visual explanations. Graphics Press, Cheshire.

Tufte, E.R. (2007). Beautiful evidence. Graphics Press, Cheshire.

van Gassel, F., Láscaris-Comneno, T., \& Maas, G. (2014). The conditions for successful automated collaboration in construction. In Automation in Construction 39, pp. 85-92. DOI: 10.1016/j.autcon.2013.12.001. 
VDI (2017). Kommunen heute und im Jahr 2030. Retrieved on 24th December

2017

https://m.vdi.de/fileadmin/user_upload/VDI-

Kommunalbefragung_Handlungsfelder.pdf
Ware, C. (2013). Information visualization, Perception for design. Waltham, MA, Morgan Kaufmann.

Zichermann, G., \& Cunningham, C. (2011). Gamification by Design. O'Reilly,

Sebastopo 